\title{
THE EFFECT OF TRIGGER POINT THERAPY AND MEDICINE BALL EXERCISES VS TRIGGER POINT THERAPY AND STRETCHING ON HIP ROTATIONAL BIOMECHANICS OF THE GOLF SWING
}

\begin{abstract}
Background: Elite golfers sustain a large number of lumbar spine injuries. Poor rotational biomechanics, which may occur as a result of a shortened iliopsoas muscle, increase the incidence of lumbar spine injuries in golfers. Stretches and medicine ball exercises are often used as part of golf training programmes in an attempt to restore hip flexor length and improve rotational biomechanics. The aim of this study was to ascertain the effect of a combination of trigger point therapy and medicine ball exercises compared to a combination of trigger point therapy and stretching on rotational biomechanics of the golf swing.
\end{abstract}

Method: This is a randomised controlled trial consisting of two experimental groups (trigger point therapy and stretching vs. trigger point therapy and medicine ball exercises) and one control group (no intervention). Hip flexor length and 3D biomechanical analysis of the golf swing was performed at baseline and one week later.

Results: One-hundred elite male golfers participated in this study. Rotational biomechanics, specifically downswing hip turn in the group that received trigger point therapy combined with medicine ball exercises, showed statistically significant improvement at reassessment compared to the control group $(p=0.0328)$.

Conclusion: Rotational biomechanics (downswing hip turn) improved following a combination of trigger point therapy treatment and a one week programme of medicine ball exercises. This is postulated to have occurred through neural reorganisation and not through improved tensile muscle strength. This improvement in rotational biomechanics has the potential to decrease lumbar spine injury incidence in elite golfers. This study advocates the use of trigger point therapy combined with medicine ball exercises in the treatment of golfers with shortened hip flexors.

KEY WORDS: GOLF SWING, BIOMECHANICS, STRETCH, MEDICINE BALL EXERCISES.

\section{INTRODUCTION}

Elite golfers - professionals and those with a handicap of less than six - sustain a large number of injuries (McHardy et al 2006). The low back is the most common injury location for golf-related injury where $18.3 \%$ of injuries sustained by golfers are located in the low back area (McHardy et al 2007). Furthermore

\section{Correspondence Author:}

Samantha-Lynn Quinn

Physiotherapy Department

Wits Medical School

7 York Road

Park Town 2193

Johannesburg, South Africa

Email: samantha.l.quinn@gmail.com
$54 \%$ of professional golfers complained of chronic ailments that prevented them from playing golf for five weeks every year (Teriault and Lachance, 1998). Most of these injuries take six months to resolve (Teriault and Lachance, 1998). This long injury recovery period means that injury prevention is essential to an elite golfer.

The lumbar spine is the most vulnerable to injury, as confirmed by Nesbit and Serrano (2005). They found that during the golf swing the lumbar spine was found to have the greatest force exerted on it. Professional golfers can reach club head speeds (CHS) of $160 \mathrm{~km} /$ hourwithin 0.2 seconds(Thériault and Lachance 1998). CHS is directly dependant on torque (Hume et al 2005), and if one considers the torque (torque $=$ moment arm $\mathrm{x}$ force) that the body must generate to produce such a large CHS it is easy to understand why the injury prevalence rate is so high. Elite golfers usually repeat this action 50 times within a round of golf ( 18 holes) or 300 or more times each practice session. Elite golfers play or practice golf for up to 10 hours a day six days a week (Thériault and Lachance 1998). This repetitive application of large forces through the lumbar spine is what causes it to be the most frequently injured area.

Poor swing biomechanics have been shown to increase the incidence of lumbar spine injuries (Sherman and Finch, 2000). The golf swing action involves a multi-lever system which aims to 
generate maximal club head speed in a precise trajectory and a wide arc of motion with the purpose of hitting a stationary ball off the ground (Thériault and Lachance 1998). During the golf swing action, the lower body plays an important role in providing a solid base from which to derive power (Hume et al 2005). The lower body generates power by providing a stable base for rotational torques and by generating ground reaction forces (Hume et al 2005). In order to increase ground reaction force the legs should be "pushed into the ground". The weight shift during the golf swing from the trail leg to the lead leg, results in a force being produced in the direction of the projectile (ball) (Hume et al 2005).

A golfer who is unable to produce adequate rotational movement (which can occur due to muscle shortening, especially of the iliopsoas muscle) will usually default to excessive lateral movement during the swing in order to generate power (Hume et al 2005). This produces two swing faults known as "sway" and "slide". "Sway" refers to an excessive lower body lateral movement away from the target during the backswing (Titleist Performance Institute, 2006). In a "sway" the golfer's centre of mass is outside the base of support. This results in the swing becoming difficult to control and excessive lateral compressive forces are placed on the lumbar spine (Baker and Newton 2005; Hume et al 2005).

"Slide" on the otherhand is a swing fault where there is excessive lower body lateral movement toward the target during the downswing (Titleist Performance Institute, 2006). This fault makes it very difficult to stabilise the lower body during the downswing and the lower body is unable to provide a stable base for the upper body (Burden et al 1998). These swing faults are detrimental in terms of injury risk as studies have shown a positive relationship between poor swing mechanics and lumbar spine injuries (Sherman and Finch 2000).

The past few years have seen a significant increase in the number of elite golfers participating in medicine ball type exercise training (plyometric resistance training) (Doan et al 2006).
It was found that resistance training reduces the incidence of lumbar spine injuries and is effective in treating lumbar spine injury (Barr et al 2005). In golf, resistance training that is combined with plyometric exercises is more sport specific than resistance training alone (Fletcher and Hartwell 2004), because resistance training combined with plyometric exercises mimics the explosive, powerful movement of the golf swing (Hume et al 2005). It also makes use of stretch-shortening cycles which are essential for good swing biomechanics (Fletcher and Hartwell 2004). A further motivation for the use of medicine ball exercises is that they recruit significantly more muscles and produce more work in the muscles they recruit relative to commonly used muscle strengthening activities such as crunches, lunges, squats and sit-ups (Petrofsky et al 2008). Studies performed by Doan et al (2006), Fletcher and Hartwell (2004) and Alverez et al (2011) have provided evidence that medicine ball exercises have the potential to change CHS and distance. There is still, however, a gap in the evidence providing support for medicine ball exercises. The studies to date are not generalisable (in that their sample sizes were small) and some essential performance indicators and injury risk predictors such as quantitative 3D swing biomechanics, were not measured. This study recruited a much larger number of participants (100 participants were recruited), thereby aiding generalisability of the results to elite male golfers between the ages of 16-25 years. Furthermore, the gold standard, namely 3D kinematic analysis, was used.

The aim of this study was to ascertain the effect of a combination of trigger point therapy and medicine ball exercises compared to a combination of trigger point therapy and stretching on rotational biomechanics of the golf swing.

\section{METHODS}

\section{Study design}

A randomised controlled trial was conducted using two experimental groups and one control group.

\section{Participants}

Elite golfers from golf academies in the greater Johannesburg area were conveniently sampled for inclusion in this study. This study required 60 participants to be powered at $90 \%$ (Thériault and Lachance 1998). To account for drop out of $40 \%$, 100 participants were recruited. To be included in the study, golfers had to present with shortened hip flexors (shortening was classified as those with a positive Modified Thomas test); have a handicap of less than six, be between 16-25 years of age, be male and be engaged in regular, golfrelated training for at least two hours per week. The age limit of 16-25 years was set as different ages have different responses to stretch (Hollard et al 2002). Different age groups also have different biomechanics (Lathey et al 2009). If the age bracket was too large this may have made the standard deviations large. The age range of 16-25 years was selected as this is usually the age that many golfers in the Gauteng area attend intensive training at golf academies (such as the Golf School of Excellence, Observatory; the Golf School of Excellence, Pretoria and Centurion Academy, Centurion). This is a crucial time in most golfers' lives and as such it is an important time to be aware of techniques that may alter performance. The reason only males were selected for this study is because males and females have different responses to stretch (Thompson and Wayne, 2004). Males were chosen over females as many more males play golf at elite level than females in South Africa. Golfers currently receiving trigger point therapy interventions independent from this study and those with known serious spinal or hip pathologies (including disc herniations, Scheuerman's disease, and fractures) were excluded. Ethical approval for the study was granted by the University of the Witwatersrand's Human Research Ethics Committee.

\section{Interventions}

Intervention 1 - Stretch Group: The stretch group received trigger point therapy combined with a week of home stretch exercise added to their routine training. 
Intervention 2 - Ball Group: The ball group received trigger point therapy followed by a week of home ball exercise added to their routine training.

\section{Intervention 3 - The Control Group} received no intervention. They were not given a home exercise programme. They were permitted to continue with routine training.

\section{Procedure}

One hundred and six participants presented themselves for participation in the study. Six participants did not meet the inclusion criteria (Figure 4). Reasons for non-inclusion were: normal hip flexor length (three participants); handicaps of more than five (two participants); older than 25 years (one participant). One hundred participants took part in the study. Each subject was allocated a participant number (in order of their arrival). Participants were randomly allocated using their participant number into one of the three groups using computer-generated table in MS Excel (stretch group $=34$, ball group $=33$, control group $=33$ ). The randomisation table was performed by a research assistant not involved in measurement or treatment during the study. He then handed the randomisation table to the physiotherapist who performed the interventions. The physiotherapist who performed the interventions then allocated each participant into a group according to the MS Excel randomisation table. In order to ensure that allocation remained concealed from the other participants, the PGA golf technician, the physiotherapist and the principal investigator, the following measures were taken: i) the physiotherapist instructed each participant not to let any of the other participants or the principle investigator or the research assistants know their group allocation; ii) each participant was kept in the treatment room for exactly the same amount of time (15 minutes); and iii) log books and home adherence tools were given to participants in opaque folders.

Each participant completed a basic demographic questionnaire consisting of questions related to age, handicap, amateur or professional golf status and medical history. The principal investigator then measured bilateral hip extension range of movement using the Modified Thomas test combined with goniometer reading (positive readings were recorded for degrees above the level of the bed, and negative readings for degrees below the level of the bed) (Clapis et al 2007).

Each participant's swing biomechanics was assessed using the 3D Golf Bio-dynamics Electromagnetic Motion Capture System $^{\circledR}$ (Polhemus Hardware, USA) by a PGA golf technician who was blinded to the hip extension measurements as well as to the group allocation. Individual calibration using anatomical marker placement described by Evans et al (2012) was done. The participant was allowed to hit as many shots as he felt he needed to become accustomed to the equipment (Gabbe et al 2004). Straight after this, each participant was given a six iron and asked to hit five balls as though he was participating in a competition where both distance and accuracy were important (Gabbe et al 2004). A report was generated showing the average value of each variable as calculated over five shots.

Both the stretch and the ball group received one session of therapy consisting of trigger point release and a static iliopsoas muscle stretch. The physiotherapist treated trigger points found in the common trigger point locations in the hip flexor muscle (Petrofsky et al 2008). The "common trigger point locations" served as a guideline, but not as an absolute rule. In order to diagnose a trigger point the physiotherapist looked for the following: a hyper-irritable point in a taut band located by palpation; the participant reported pain that referred to a distal point when pressure was applied to the trigger point; a local twitch response in the muscle was elicited when pressure was applied to the trigger point; the participant flinched away from palpation. The physiotherapist treated the trigger point using ischaemic pressure (minimum of 45 seconds of pressure per trigger point). After the ischaemic pressure the participants received a 60 second stretch of the iliopsoas muscle (Petrofsky et al 2008). This stretch was performed by the participant placing one leg on the plinth while the rest of the body remained erect (half kneel position). The participant's pelvis remained in neutral alignment and the participant was instructed to move his centre of mass anteriorly until he felt a stretch in the iliopsoas muscle.

The participants in the stretch group were instructed to do an additional 60 second static stretch of iliopsoas muscle in half kneeling position. The participants moved their pelvis forward without allowing anterior pelvic tilt. They were instructed to perform this stretch for 60 seconds each side three times a day, every day for the following week. The stretch group continued with their routine training. The stretch group were shown the ball exercise that the ball group was given and asked not to perform this specific exercise for the week of the study.

The participants in the ball group were instructed to perform the ball exercise. This exercise involved the following proprioceptive neuromuscular facilitation (PNF) pattern with a $4 \mathrm{~kg}$ ball: the participant starts in a squat with the hands holding the ball to the side of the body then the participant stands up, raising the ball above the head to the opposite side of the body as shown in Figure 1. Participants were instructed to repeat this movement 50 times to each side. The ball group were then instructed to perform the ball exercise three times per day for one week. The ball group continued with their routine training. They were shown the specific stretch that the stretch group had been given and they were asked not to perform this stretch for the week of the study (Doan et al 2006).

Participants from the control group remained in the treatment room for the same period of time (15 minutes) as participants from the other groups. The control group were shown the ball exercise that the ball group was given and the stretch that the stretch group was given. The control group participants were asked not to perform these exercises for the week of the study.

All participants were asked to record the time (in 15 minute intervals) spent on each routine training activity (e.g. postural training, weight training, 
practice at the driving range) for the following week, in a logbook.

All participants underwent a second hip extension range of movement assessment and the 3D swing analysis assessment one week after the baseline measures were taken.

\section{Data analysis}

Data were analysed using STATA Data Analysis and Statistical Software ${ }^{\circledR}$ (version 11.2; Texas: USA). Means and standard deviations were calculated. The one way analysis of co-variance test (ANCOVA) was used to adjust for
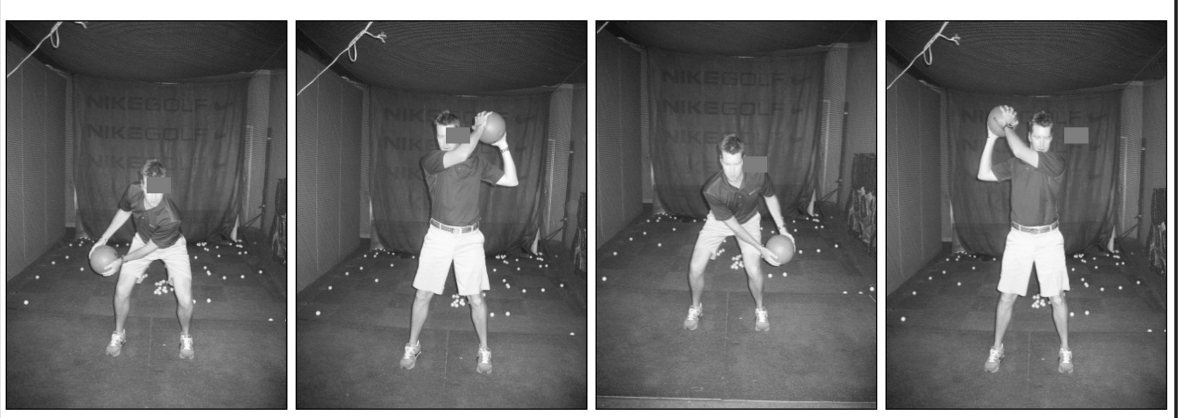

Figure 1: The Prescribed Ball Exercise for Muscle Activation

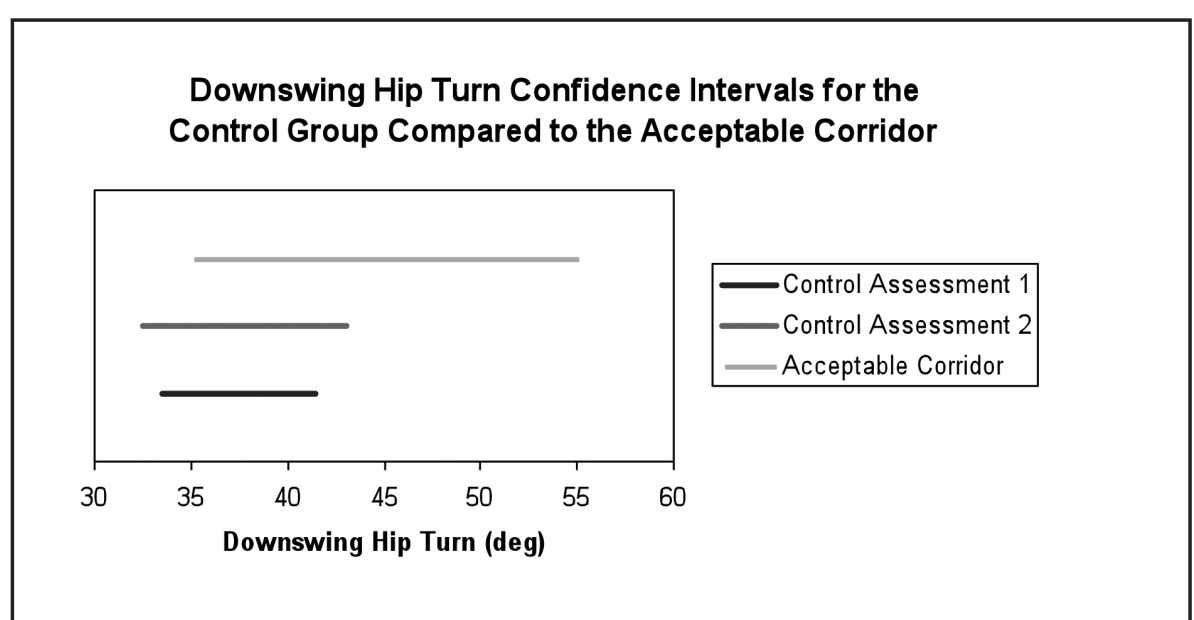

Figure 2: Downswing hip turn intervals for the control group at Assessment 1 and Assessment 2 compared to the acceptable corridor

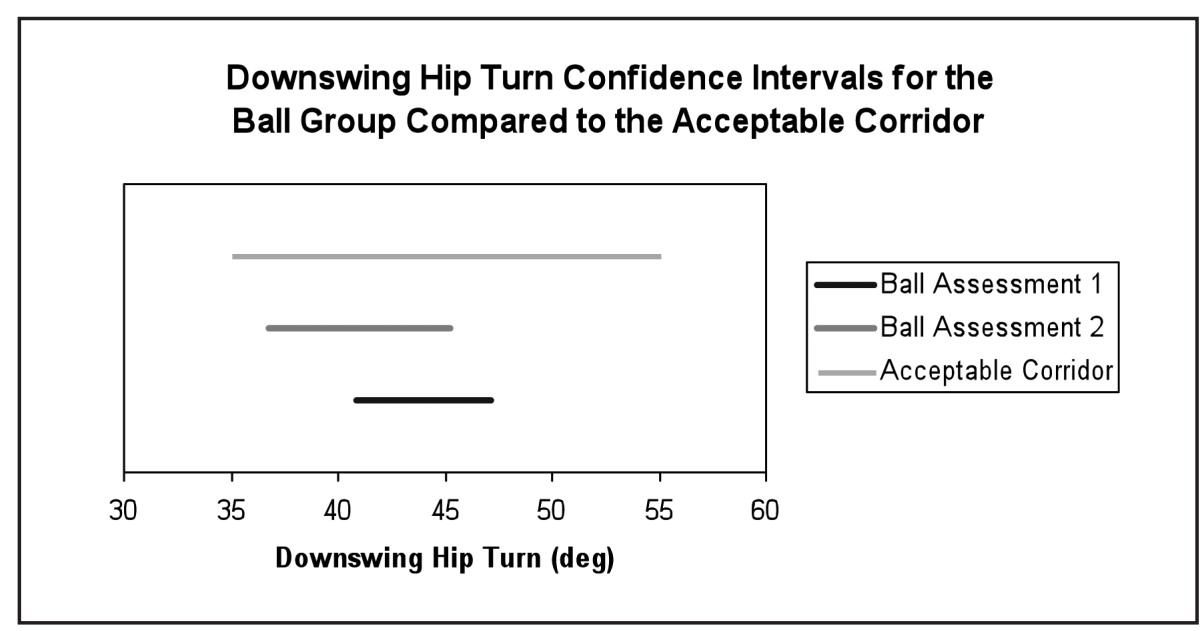

Figure 3: Downswing hip turn intervals for the ball group at Assessment 1 and Assessment 2 compared to the acceptable corridor

differences in baseline while comparing the variables of interest between the control group and the stretch group; and between the control group and the ball group. Confidence intervals were calculated for statistically significant results in order to find out if the 'true value' was within the accepted clinical corridors or not. Accepted clinical corridors for each biomechanical variable were based on findings from the literature (Horan et al 2010). When a measurement falls outside the acceptable corridor it is considered as faulty biomechanics. This was done to determine if the results were clinically significant or only statistically significant. Significance was set at $\mathrm{p}=0.05$.

\section{RESULTS}

One hundred participants took part in this study. Figure 4 indicates the study procedure by means of a flow diagram. Demographic and anthropometric data are shown in Table 1.

The acceptable corridor for downswing hip turn is $35^{\circ}$ to $55^{\circ}$. This corridor is supported by the mean obtained in a study performed by Horan et al in 2010. The confidence interval for the control group at Assessment 1 was $33.488^{\circ}<\mu<41.400^{\circ}$ and at Assessment 2 was $32.555^{\circ}<\mu<43.087^{\circ}$ (Figure 2). This shows that with routine training downswing hip turn moved more outside of the acceptable corridor indicating a worsening of rotational biomechanics. The confidence interval for downswing hip turn for the ball group at Assessment 1 was $40.812^{\circ}<\mu<47.188^{\circ}$ and at Assessment 2 was $36.799^{\circ}<\mu<45.201^{\circ}$ (Figure 3). This showed that the ball group remained within the accepted range and had improved rotational biomechanics relative to the control group ( $p=0.0328$ ) (Table 2). The stretch group showed no change in rotational biomechanics ( $\mathrm{p}=0.1248$ ) (Table 2).

Differences between groups in terms of flexibility training, weight training and total training had no effect on the significance of the results obtained (i.e. the statistically significant results stayed significant even when differences in training were adjusted for). Hip extension range of movement did not 
change when measured at reassessment one week later (stretch vs. control group - left hip $\mathrm{p}=0.23$, right hip $\mathrm{p}=0.92$; ball vs. control group - left hip $\mathrm{p}=0.55$, right hip $\mathrm{p}=0.44$ ).

\section{DISCUSSION}

The trigger point therapy followed by a week of ball exercise was able to produce significant improvements in rotational biomechanics (downswing hip turn). As poor rotational biomechanics is associated with back pain, improved rotational biomechanics caused by the ball exercise could potentially result in decreased lumbar spine injury incidence. The trigger point therapy followed by a week of home stretching resulted in no significant changes in hip flexor length or biomechanics. From a therapeutic perspective this study advocates the use of trigger point therapy followed by movement preparation type exercises (such as the medicine ball exercise) over the use of trigger point therapy combined with a week of stretching in the treatment of elite male golfers with shortened hip flexors and the prevention of lumbar spine injuries in elite golfers.

As both the ball and stretch group received trigger point therapy and only the ball group saw improvements in rotational biomechanics; the improvement in rotational biomechanics is proposed to have occurred primarily through ball exercise and not the trigger point therapy intervention. The proposed mechanism for the improved rotational biomechanics in the ball group was improved muscle control in the pelvic area. This is postulated to have occurred through neural reorganisation and not through improved tensile muscle strength (Bird et al 2005). In order to perform the ball exercise correctly the golfer would have to control concentric and eccentric loading of the iliopsoas muscle. For a golfer to achieve good backswing hip rotational biomechanics he must eccentrically lengthen the right iliopsoas muscle (controlling hip internal rotation) and concentrically contract the left iliopsoas muscle (produce hip external rotation). In order to achieve good follow-through hip rotational biomechanics he must eccentrically lengthen the left iliopsoas muscle (controlling hip internal rotation) and concentrically contract the right iliopsoas muscle (so as to produce hip external rotation and hip extension) (Torres et al 1995). Good rotational biomechanics at the hips are essential for developing power (Hume et al 2005). If a golfer was unable to utilise good hip rotational biomechanics it is postulated that he will try to gain power by use of excessive ground reaction forces (seen in the swing as a "sway" or "slide" swing

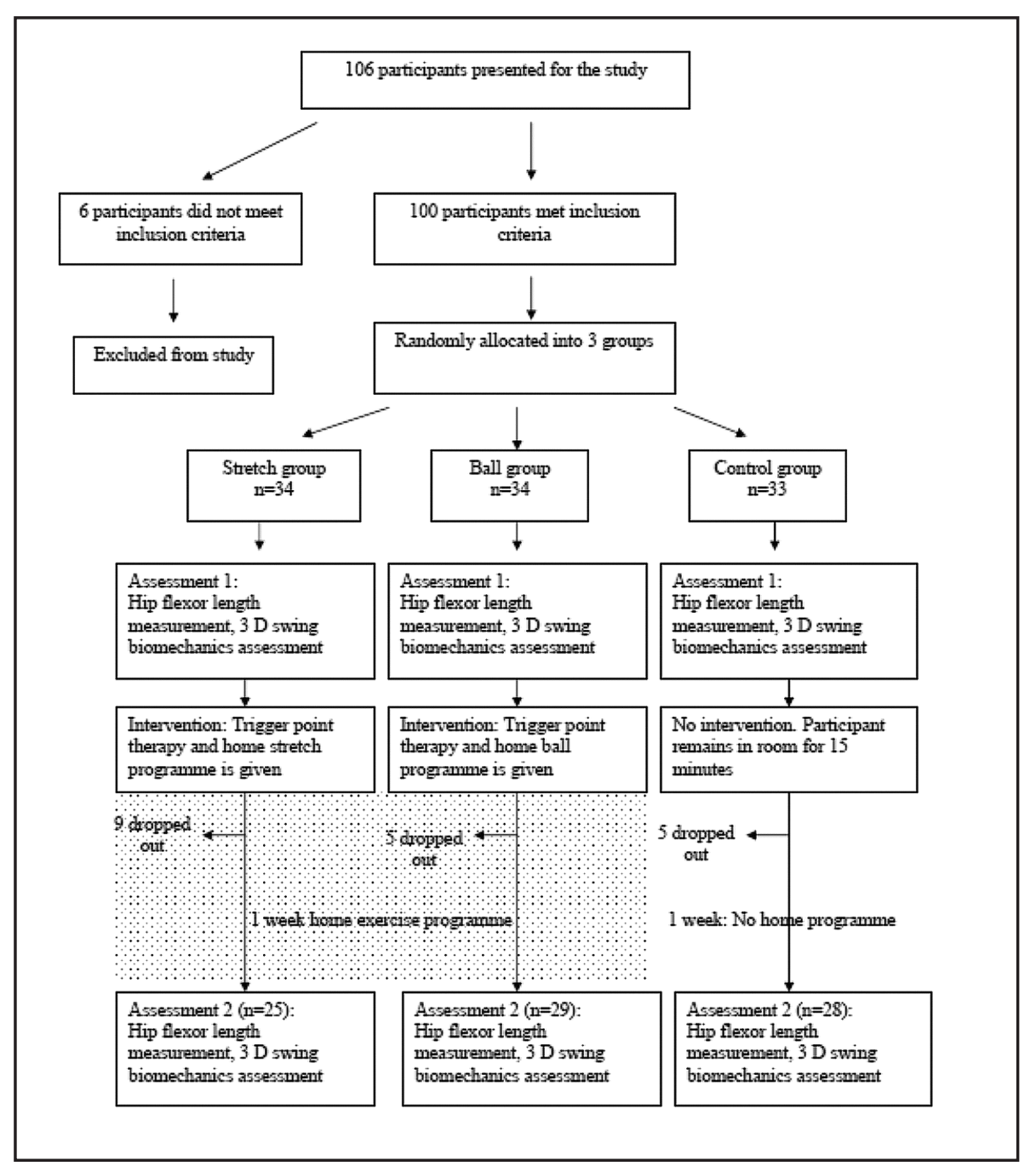

Figure 4: Flow diagram of study procedure

Table 1: Demographic and Anthropometric Data

\begin{tabular}{|l|l|l|l|l|}
\hline Variable & Statistic & $\begin{array}{l}\text { Control (Group 3) } \\
\mathrm{n}=33\end{array}$ & $\begin{array}{l}\text { Stretch (Group 1) } \\
\mathrm{n}=34\end{array}$ & $\begin{array}{l}\text { Ball (Group 2) } \\
\mathrm{n}=33\end{array}$ \\
\hline Age & Mean (SD) (yrs) & $20(2.0)$ & $20(1.5)$ & $20 .(2.0)$ \\
\hline Handicap & Mean (SD) & $-2(2.6)$ & $-1(2.3)$ & $-3(2.2)$ \\
\hline Weight & Mean (SD) (kg) & $80.70(11.566)$ & $77.85(11.784)$ & $74.58(11.729)$ \\
\hline Height & Mean (SD) (m) & $1.80(0.055)$ & $1.80(0.081)$ & $1.77(0.088)$ \\
\hline BMI & $\begin{array}{l}\text { Mean (SD) } \\
\left(\mathrm{kg} / \mathrm{m}^{2}\right)\end{array}$ & $25(3.7)$ & $24(2.9)$ & $24(3.3)$ \\
\hline
\end{tabular}


Table 2: Between-group change in biomechanics from Assessment 1 to Assessment 2 (stretch versus control; ball versus control)

\begin{tabular}{|c|c|c|c|c|}
\hline Variable & Statistic & $\begin{array}{l}\text { Control Group } \\
(n=28)\end{array}$ & $\begin{array}{l}\text { Stretch Group } \\
(\mathrm{n}=25)\end{array}$ & $\begin{array}{l}\text { Ball Group } \\
(n=29)\end{array}$ \\
\hline \multirow{2}{*}{$\begin{array}{l}\text { Change in Hip Alignment } \\
\text { at Address }\end{array}$} & Mean $(\mathrm{SD})\left(^{\circ}\right)$ & $0.000(4.225)$ & $1.320(6.046)$ & $0.448(6.572)$ \\
\hline & $p$-value & & 0.6632 & 0.4881 \\
\hline \multirow[t]{2}{*}{ Change in 'Pelvic bending' (AP) } & Mean $(S D)\left({ }^{\circ}\right)$ & $-1.464(12.761)$ & $0.960(11.696)$ & $6.966(12.330)$ \\
\hline & p-value & & 0.2285 & 0.3184 \\
\hline \multirow{2}{*}{$\begin{array}{l}\text { Change in Pelvic tilting' } \\
\text { (Lateral Flexion at Address) }\end{array}$} & Mean $(\mathrm{SD})\left(^{\circ}\right)$ & $-0.786(3.804)$ & $-0.720(3.129)$ & $-0.655(4.099)$ \\
\hline & $\mathrm{p}$-value & & 0.3950 & 0.7037 \\
\hline \multirow[t]{2}{*}{ Change in Backswing hip turn } & Mean (SD) $\left(^{\circ}\right)$ & $-0.036(6.269)$ & $-0.520(7.338)$ & $-2.448(7.600)$ \\
\hline & p-value & & 0.7034 & 0.3013 \\
\hline \multirow[t]{2}{*}{ Change in X-Factor } & Mean $(\mathrm{SD})\left(^{\circ}\right)$ & $0.000(9.471)$ & $-2.120(5.600)$ & $-0.207(9.424)$ \\
\hline & $\mathrm{p}$-value & & 0.6453 & 0.2836 \\
\hline \multirow[t]{2}{*}{ Change in X-Factor Stretch } & Mean $(S D)\left({ }^{\circ}\right)$ & $0.643(3.165)$ & $0.960(3.931)$ & $-3.000(6.756)$ \\
\hline & p-value & & 0.8703 & 0.2038 \\
\hline \multirow[t]{2}{*}{ Change in Backswing Hip Drop } & Mean (SD) (cm) & $-0.071(0.714)$ & $-0.008(0.896)$ & $-0.038(0.903)$ \\
\hline & $p$-value & & 0.6443 & 0.8930 \\
\hline \multirow[t]{2}{*}{ Change in Backswing Hip Sway } & Mean (SD) $(\mathrm{cm})$ & $0.425(1.812)$ & $0.664(2.474)$ & $0.297(2.071)$ \\
\hline & $\mathrm{p}$-value & & 0.9853 & 0.5174 \\
\hline \multirow{2}{*}{$\begin{array}{l}\text { Change in Downswing Hip Turn } \\
\text { (Impact Zone) }\end{array}$} & Mean (SD) $\left(^{\circ}\right)$ & $-1.286(5.792)$ & $1.840(6.980)$ & 3.517 (8.105) \\
\hline & $p$-value & & 0.1248 & $* 0.0328$ \\
\hline \multirow{2}{*}{$\begin{array}{l}\text { Change in Downswing Hip tilt } \\
\text { Lateral Flexion }\end{array}$} & Mean (SD) $\left(^{\circ}\right)$ & $-1.607(4.467)$ & $-0.440(2.725)$ & $-0.759(4.323)$ \\
\hline & $\mathrm{p}$-value & & 0.3782 & 0.8256 \\
\hline \multirow{2}{*}{$\begin{array}{l}\text { Change in Downswing Hip bend } \\
\text { Flexion }\end{array}$} & Mean (SD) $\left(^{\circ}\right)$ & $0.429(13.192)$ & $1.000(11.712)$ & $6.931(13.575)$ \\
\hline & $p$-value & & 0.5554 & 0.3779 \\
\hline \multirow{2}{*}{$\begin{array}{l}\text { Change in Downswing Hip Sway } \\
\text { (Address to Impact) }\end{array}$} & Mean (SD) $(\mathrm{cm})$ & $0.407(1.751)$ & $-0.112(2.051)$ & $0.324(2.087)$ \\
\hline & $\mathrm{p}$-value & & 0.3895 & 0.6121 \\
\hline \multirow[t]{2}{*}{ Change in Downswing Hip Thrust } & Mean $(\mathrm{SD})(\mathrm{cm})$ & $-0.107(1.223)$ & $-0.044(1.294)$ & $0.131(1.450)$ \\
\hline & $\mathrm{p}$-value & & 0.8764 & 0.3893 \\
\hline \multirow[t]{2}{*}{ Change in Downswing Hip Speed } & Mean (SD) $(\% / s e c)$ & $-10.536(49.760)$ & $3.760(158.368)$ & $8.276(84.171)$ \\
\hline & p-value & & 0.9440 & 0.6237 \\
\hline
\end{tabular}

Negative values indicated an increase in the variable measured. Positive values indicated decrease in the variable measured. One way analysis of co-variance test (ANCOVA) was used to adjust for differences in baseline while comparing the variables of interest between the control group and the stretch group; between the control group and the ball group.

fault). Poor hip rotational biomechanics and excessive lateral movement during the golf swing have been associated with lumbar spine injury (Sherman and Finch 2000).

The medicine ball exercises chosen were sport specific. It encouraged squatting and extending of the hip within the golfers' normal competition range. Contraction of the gluteus muscle during extension from the squat results in reciprocal inhibition of the iliopsoas muscle. The hip extension produced when coming out of the squat acts as a dynamic, movement-specific stretch on iliopsoas muscle. Dynamic reciprocalinhibition stretching has been shown to increase range of movement (Baker and Newton 2005). As all participants in this study presented with shortened iliopsoas muscles, the addition of ball exercises to the trigger point therapy may have resulted in improved rotational biomechanics through the mechanism described above. This improvement in rotational biomechanics in the medicine ball exercise group may be associated with decreased injury risk and improved performance.

Based on the inclusion criteria, the results from this study could be generalised to male elite golfers between the ages of 16-25 years with handicaps lower than six. Caution is advised when applying these results to females, older males and high handicap players as 
they have different swing biomechanics (Lathey et al 2009). Additionally, females and older males respond differently to stretch (Hollard et al 2002; Thompson and Wayne 2004). Passive muscle stiffness is greater in males than in females (Morse 2011). Older males tend to respond worse to stretch than their younger males (Hollard et al 2002) and may therefore not respond as well to the dynamic stretch provided by the medicine ball exercise as their younger male counterparts.

A limitation of this study was the short study period of one week. As such, the effects of long term trigger point therapy and long term ball exercises or stretch on biomechanics was not assessed. It is important to note that one week of ball exercises is not sufficient to produce hypertrophic changes to the muscle. Visible hypertrophic muscle change usually occurs after approximately eight weeks of resistance training (it is, however, important to note that protein synthesis occurs after the first resistance training session) (Bird et al 2005). The week of medicine ball exercises can, however, result in increased muscle strength by means of neural adaptation (Bird et al 2005). Possible neural adaptations are: increased motor neurone firing rate; double firing of the motor unit; motor unit synchronisation.

\section{CONCLUSION}

Shortened hip flexors predispose golfers to poor rotational biomechanics. Poor rotational biomechanics are associated with lumbar spine injury. The large lumbar spine injury incidence in elite golfers necessitates investigation into techniques that help prevent injury (such as improving rotational biomechanics). Health care, fitness and training professionals often recommend routine stretching to golfers with shortened hip flexors. Based on the results from this study, a plyometric exercise, like the medicine ball exercise described in this article, may be more beneficial in treating elite golfers with shortened hip flexors). Future studies should be done on the effect of exercise programmes over time (consistent use) on golf swing biomechanics and subsequent injury prevention.

\section{REFERENCES}

Alvarez M, Sedano S, Cuadrado G, Redondo JC 2011. Effects of an 18-week strength training program on low-handicap golfers' performance. Journal of Strength \& Conditioning Research (Allen Press Publishing Services Inc.) 0: 1-12.

Baker D, Newton, RU 2005. Acute effect on power output of alternating an agonist and antagonist muscle exercise during complex training. Journal of Strength and Conditioning Research 19: 202205

Barr KP, Griggs M, Cadby T 2005. Lumbar stabilization: core concepts and current literature, part 1. American journal of physical medicine \& rehabilitation 84: 473

Bird SP, Tarpenning KM, Marino FE 2005 Designing resistance training programmes to enhance muscular fitness: a review of the acute programme variables. Sports Medicine 35: 841-851

Burden AM, Grimshaw PN, Wallace ES 1998. Hip and shoulder rotations during the golf swing of sub-10 handicap players. Journal of Sports Sciences 16: 165-176

Clapis PA, Davis SM, Davis RO 2007. Reliability of inclinometer and goniometric measurements of hip extension flexibility using the modified Thomas test. Physiotherapy Theory and Practice 24: $135-141$

Doan BK, Newton RU, Kwon YH, Kraemer WJ 2006. Effects of physical conditioning on intercollegiate golfer performance. Journal of Strength and Conditioning Research 20: 62-72

Evans K, Horan SA, Neal RJ, Barrett RS, Mills PM 2012. Repeatability of three-dimensional thorax and pelvis kinematics in the golf swing measured using a field-based motion capture system. Sports Biomechanics 11: 262-272

Fletcher IM, Hartwell M 2004. Effect of an 8-week combined weights and plyometrics training program on golf drive performance. The Journal of Strength \& Conditioning Research 18: 59-62

Gabbe, BJ, Bennell, KL, Wajswelner, H, Finch, CF 2004. Reliability of common lower extremity musculoskeletal screening tests. Physical Therapy in Sport 5: 90-97

Hollard GJ, Tanaka K, Shingematsu R, Nakagaichi M 2002. Flexibility and physical functions of older adults: a review. Journal of Aging and Physical Activity 10:169-206

Horan SA, Evans K, Morris NR, Kavanagh JJ 2010. Thorax and pelvis kinematics during the downswing of male and female skilled golfers. Journal of Biomechanics 43: 1456-1462
Hume PA, Keogh J, Reid D 2005. The role of biomechanics in maximising distance and accuracy of golf shots. Sports Medicine 35: 429-449

Lathey C, Strike S, Lee R 2009. The effects of aging on the hip and spinal motions in the golf swing $27^{\text {th }}$ International Conference on Biomechanics in Sport, University of Limerick, Ireland, Limerick 17-21 August 2009.

McHardy A, Pollard H, Luo K 2006. Golf injuries: a review of the literature. Journal of Sports Medicine 36:171-187

McHardy A, Pollard H, Luo K 2007. One-year follow-up study on golf injuries in Australian amateur golfers. American Journal of Sports Medicine 35: 1354-60

Morse CI 2011. Gender differences in the passive stiffness of the human gastrocnemius muscle during stretch. European Journal of Applied Physiology 111: 2149-2154

Nesbit S and Serrano M 2005. Work and Power Analysis of the Golf Swing. Journal of Sports Science and Medicine 15: 520-533

Petrofsky J, Prowse M, Lemoine M, Bartelink T, Batt J, Suh J, Furr A, Jauregui A, Dick A, Retzer G, Harper R, Bouterie R, Brown J, Leyva J, Charbonnet M, Stacey L, Bains G 2008. Muscle use during exercise on a mini medicine ball compared to other abdominal exercise modalitites. Journal of Applied Research 8: 95-115

Sherman CA, Finch CF 2000. Preventing injuries to competitive and recreational adult golfers: what is the evidence? Journal of Science and Medicine in Sports 3: 65-78

Thériault G, Lachance P 1998. Golf injuries. Sports Medicine 26: 43-57

Titleist Performance Institute 2006. Titlest Performance Institute Certified Seminar Manual Level 1. Acushnet Company

Thompson C, Wayne H 2004. Effects of an 8-week multimodal exercise program on strength, flexibility and golf performance in 55- to 79-yearold men. Journal of Aging and Physical Activity 12: $144-13$

Torres GM, Cernigliaro JG, Abbitt PL, Mergo PJ, Hellein VF, Fernandez S, Ros, PR 1995. Iliopsoas compartment: normal anatomy and pathologic processes. Radiographics 15: 1285-1297 


\section{STUDYING PHYSIOTHERAPY AT THE UNIVERSITY OF THE WITWATERSRAND}

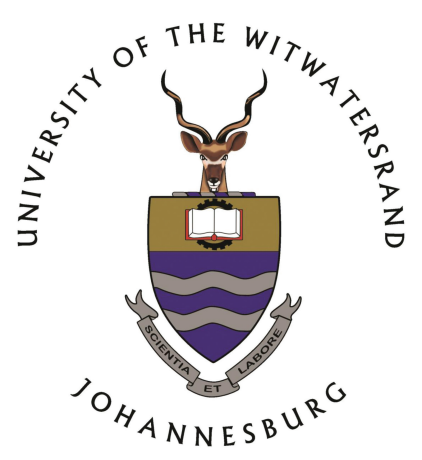

$T$ he physiotherapy department at the University of the Witwatersrand is committed to developing the highest standards of academic and clinical excellence. We aim to produce responsible innovative, critically thinking professionals committed to meeting the health needs of all the communities in South Africa, appropriately and cost effectively.

Physiotherapy forms part of the health care profession and we often work as part of a multidisciplinary team when treating patients. As first line practitioners, patients are able to come to physiotherapy with their health needs without being referred by a doctor.

We aim to better patients' quality of life through improving their ability to carry out activities of daily living. Physiotherapy aims to restore human functional ability, maintain mobility, strength and endurance.

\section{UNDERGRADUATE ENTRANCE REQUIREMENTS}

\section{MINIMUM ENTRY REQUIREMENTS:}

- Matriculation exemption,

- English,

- Mathematics,

- Life Sciences and or Physical Sciences

A minimum of $70 \%$ pass in each subject is required. It should however be noted that for the School of Therapeutic Sciences (Physiotherapy included), you will not be selected solely on your school leaving results, although they are very important. A composite index is calculated, taking into consideration (1) your academic results for FIVE subjects; (2) Health Sciences Selection Test scores (National Benchmark Test - NBT); (3) the score you achieved for the Biographical Questionnaire.
The Faculty of Health Sciences does not calculate an Admissions Points Score (APS). Only five subjects are used to derive a matriculation score, which is calculated according to the percentages obtained, NOT symbols. These are English, Mathematics, Physical Science/Life Sciences and the best two other subjects.

ALL applicants are required to write the Health Sciences Selection Tests (National Benchmark Test - NBT).

*All applicants are expected to have spent some time in a physiotherapy department in order to gain some first hand knowledge of what the job entails.

\section{COURSE DURATION AND WORKLOAD}

The course requires 4 years of full-time study. The first year is based at the University of the Witwatersrand main campus while years 2 to 4 are based at the Faculty of Health Sciences in Parktown. In the $3^{\text {rd }}$ year of study, preclinical teaching at the beginning of the year is followed by students doing clinical work in the mornings in various hospitals, schools and clinics in Gauteng. Lectures, tutorials and practicals take place in the afternoons. In the $4^{\text {th }}$ year of study, pre-clinical teaching at the beginning of the year is followed by students working in various hospitals the whole day. Students are also required to spend 4 weeks at a rural hospital as part of their Public Health block. The course is time consuming and involves considerable commitment from the students.

Please note that all new graduates serve a period of 1 year compulsory community service. 


\section{POSTGRADUATE COURSES}

The Physiotherapy Department offers the following Postgraduate courses:

- Postgraduate Diploma in Physiotherapy

- MSc (Physiotherapy) by Coursework and Research Report

- MSc (Physiotherapy) by Dissertation

- $\mathrm{PhD}$

\section{MSc (COURSEWORK)}

(All courses are done as "block release" modules)

This department offers specialisation course work in the following areas:

- Orthopaedics for Physiotherapists

- Respirology, cardiology and cardiothoracic surgery for physiotherapists

- Community Physiotherapy

- Traumatology for Physiotherapists

- Neurology and Neurosurgery for Physiotherapists

- Sport and Exercise Physiotherapy

- Paediatrics (General or Neurology)

- Orthopaedic Manipulative Therapy (OMT)

- Physiotherapeutic Musculoskeletal Pain Management

Students are expected to be clinically working in the area of speciality. These courses are done over a period of two to three years using a block release system. The first year of MSc coursework consists of Anatomy, Physiology and Pathology courses. The second year of coursework involves the curriculum taught for the above mentioned subject chosen. The student will also be expected to complete a research report as part of the coursework masters programme. The research component makes up $50 \%$ of the degree.

\section{MSC BY DISSERTATION}

Students can register research topics with the department, then put together a research proposal and submit an application form for ethical clearance. The research proposal is first presented to the Physiotherapy Department and will, after approval, be submitted to the School of Therapeutic Sciences' assessors. Students are required to attend the research methodology course before putting together their research proposal.

\section{PhD}

Students can register research topics with the department, then put together a research proposal and submit an application for ethical clearance. The research proposal is first presented to the Physiotherapy Department and will, after approval, be submitted to the Faculty of Health Sciences' postgraduate committee.

\section{ENTRY REQUIREMENTS}

General information and Entry Requirements for the MSc Physiotherapy (coursework and research report), MSc (Physiotherapy) (dissertation) and Post Graduate Diploma in Physiotherapy.

- All applicants for the Post Graduate diploma and Masters degrees must hold a BSC (Physiotherapy) degree.

- Applicants for a PhD must hold the same as well as a Master's degree.

- To be eligible for the Post Graduate diploma and the MSc (Physiotherapy) coursework, applicants must show evidence of two years of clinical experience one of which can be the community service year.

\section{WHY STUDY PHYSIOTHERAPY AT THE UNIVERSITY OF THE WITWATERSRAND?}

The academic staff in the physiotherapy department has among it 7 lecturers with PhDs with a further 6 who are either almost done with their PhD studies or are busy with their data collection. The department is an active research entity that publishes proficiently in national and international journals. The research that is done in the department informs what is taught and hence influences patient management greatly in the clinics and hospitals.

Our undergraduates are sought after nationally and internationally. We also have a vibrant postgraduate programme with over $60 \mathrm{MSc}$ and have $16 \mathrm{PhD}$ students at various stages of their studies or research programmes.

For individuals who want to be responsible, innovative and critically thinking physiotherapy professionals, The University of the Witwatersrand is the place of choice. 
